\title{
Components of reflexive visual orienting to moving objects
}

\author{
TONY RO and ROBER'T D. RAFAL \\ University of California, Davis, California \\ and VAHCS, Martinez, Califormia
}

\begin{abstract}
Posner and Cohen (1984) and Maylor (1985) initially observed that a luminance change produces both facilitatory and inhibitory effects on subsequent detection. While Posner and Cohen claimed that the facilitatory effect was mapped in retinotopic coordinates, they showed that inhibition of return (IOR) was mapped in "environmental coordinates." Tipper and colleagues (Tipper, Driver, \& Weaver, 1991; Tipper et al., 1997; Tipper, Weaver, Jerreat, \& Burak, 1994) and Abrams and Dobkin (1994b) have recently reported that IOR can be object based, but contradictory results have also been reported (Müller \& von Mühlenen, 1996). Here we report six experiments showing that an uninformative peripheral cue can generate either facilitatory or inhibitory object-based effects that can tag moving objects and that can persist for several hundred milliseconds. Although the boundary conditions determining which effect will be manifest remain to be defined, the present results suggest that facilitation and inhibition are generated independently, rather than being components of the same biphasic process.
\end{abstract}

The present study investigated the effects of exogenously activated orienting of attention on the subsequent detection of targets appearing in objects that have moved. Posner and Cohen (1984) demonstrated that, following a peripheral change in luminance, there is an initial facilitation of detection succeeded by a subsequent inhibition at the cued location (see also Maylor, 1985; Maylor \& Hockey, 1985). However, Tassinari, Aglioti, Chelazzi, Peru, and Berlucchi (1994) have proposed that rather than a biphasic modulation of detection reaction time (RT), as originally suggested, there is a co-occurrence of separate and independent facilitatory and inhibitory effects following peripheral, uninformative cues (for similar accounts, see Egly, Rafal, Henik, \& Berger, in press; Gibson \& Egeth, 1994; Rafal, Egly, \& Rhodes, 1994; Rafal \& Henik, 1994; Tanaka \& Shimojo, 1996; Tipper et al., 1997). Tassinari et al. claimed co-occurrence by showing that inhibition can be present at short cue-to-target intervals, previously presumed to involve only the facilitatory effect. They argued that the facilitatory effect was transient, that it was generated only under restricted conditions of stimulation, and that the inhibition, or the inhibitory aftereffect, as they called it, was the dominant effect of orienting to exogenous signals.

Posner and Cohen (1984) called this inhibitory phenomenon inhibition of return (IOR) and discussed its role in

The authors thank Liana Machado and Harris Ingle for help with data collection. We also thank Todd Horowitz for helpful suggestions made on an earlier version of this manuscript. This work was supported by US PHS Grant MH41544 to R.D.R. and by US PHS training fellowship MH19930 to T.R. Correspondence should be addressed to T. Ro, Department of Psychology-MS 25, Rice University, 6100 Main St., Houston, TX 77005-1892 (e-mail: tro@rice.edu).

-Accepted by previous editor, Myron Braunstein the visual system to favor novelty. They presented evidence that the facilitatory effect of orienting was manifest in retinotopic coordinates, whereas IOR was manifest in environmental coordinates. Further evidence suggesting that IOR is manifest in extraretinal coordinates has recently come from studies demonstrating that IOR exists not only to locations in space, but also to objects that move (Abrams \& Dobkin, 1994b; Gibson \& Egeth, 1994; Tipper, Driver, \& Weaver, 1991; Tipper et al., 1997; Tipper, Weaver, Jerreat, \& Burak, 1994). In the studies by Tipper et al., for example, a peripheral object was cued by a brief brightening. Following the peripheral exogenous cue, the objects were made to move while the fixation point was cued, and comparisons between response latencies made to targets that appeared in a previously cued object versus an uncued object were made. The RTs were slower when the target appeared in the previously cued object than when it appeared in the uncued object. Because IOR was obtained in these objects, which were not restricted to a visual location, Tipper et al. called this effect object-based IOR.

Using this same paradigm to investigate object-based IOR, Tipper et al. (1997) have demonstrated that in splitbrain patients, whose corpus callosum connecting the two hemispheres of the brain has been resected to treat severe epilepsy, both an object-based facilitation and an objectbased IOR could be produced by the same stimulus. The facilitatory effect was revealed when the objects moved between the "disconnected" hemifields, whereas objectbased IOR was manifest when the objects moved but stayed within a hemifield. Tipper et al. concluded that the facilitatory and inhibitory components of visual orienting were coexistent, similar to the conclusions drawn by Tassinari et al. (1994). It was also argued that object-based IOR was transferred between cortical hemispheres through the corpus callosum while the facilitatory effect was trans- 
ferred subcortically. In contrast to the account proposed by Tassinari et al., however, Tipper et al. showed that the facilitatory effect was not necessarily transient and that IOR was not necessarily the dominant effect of exogenous orienting.

Although object-based IOR from an ecological standpoint seems like an adaptive mechanism, since objects in the visual world are often moving, it is not always experimentally observed (Müller \& von Mühlenen, 1996) and may critically depend on the specific experimental parameters (Tipper et al., 1994). The present experiments were intended to demonstrate in neurologically normal individuals that a luminance change occurring in an object produces a facilitatory tag that persists long enough to move with the object. Given the findings in the split-brain patients, we reasoned that either facilitatory or inhibitory tags could be generated, or possibly both concurrently, and that the net effect on detection performance could critically depend on experimental parameters that might preferentially bias either the facilitatory or the inhibitory effect. The two main factors manipulated in this series of experiments were the motion parameters and the control of attention at fixation.

The present study began by investigating the influence of different types of apparent motion (AM) displays, short range and long range, in generating object-based orienting effects. Since it has been suggested that different neural mechanisms are involved in the processing of short-range and long-range AM (Mikami, 1991), and also since perception of the two types of AM is differentially influenced by attention (Dick, Ullman, \& Sagi, 1987; Horowitz \& Treisman, 1994; Ivry \& Cohen, 1990; Mack et al., 1991), contrasting object-based attentional orienting effects in the two types of AM might be expected. Furthermore, the type of motion used in the studies by Tipper et al. (1991; Tipper et al., 1997; Tipper et al., 1994) was somewhat ambiguous, since a mixture of the parameters for both shortand long-range AM was used (Braddick, 1974; Chang \& Julesz, 1983; Petersik, 1989; Rock, 1983). ${ }^{1}$ Because there were no interstimulus intervals (ISIs) between the frames of motion and yet there were large spatial separations between the boxes in each frame (approximately $1.4^{\circ}$ ), it is unclear which AM mechanisms may be involved in their observed effect. We reasoned that object-based orienting effects might more reliably be revealed under one type of motion display than the other. Our initial goal in the present experiments was to attempt to demonstrate both facilitatory and inhibitory object-based effects of exogenously summoned attention in normals that might be manifest under the short-range and long-range AM conditions, respectively. Since in the initial experiments the type of AM, whether short range or long range, did not produce any consistent differences in generating objectbased facilitation or IOR, subsequent experiments manipulated the fixation point in an effort to dissociate these components of reflexive visual orienting.

\section{EXPERIMENT 1}

The goal of this experiment was to compare the orienting of attention to objects undergoing short-range and long-range AM using a simple RT detection task. The type of motion used in Tipper et al. (1991; Tipper et al., 1997; Tipper et al., 1994), as mentioned in the introduction, was somewhat ambiguous since the temporal separations of the motion frames favored the short-range process, but the spatial separations were large, favoring the long-range process of AM. We therefore used both shortand long-range AM in this experiment to determine whether object-based facilitation and object-based IOR are only present with specific types of motion.

\section{Method}

Apparatus. All of the experiments were conducted on an IBMcompatible personal computer connected to an NEC Multisync video graphics array (VGA) stimulus monitor. The graphics mode was set to a $640 \times 480$ pixel resolution using Borland's Graphics Interface. The timing of the visual displays was synchronized with the vertical synchronization of the computer monitor at $16^{2 / 3}-\mathrm{msec}$ intervals $(60 \mathrm{~Hz}){ }^{2}$ Millisecond timing, used to obtain response latencies, was achieved by setting the 8253 chip of the computer to millisecond ticks. Responses were made on a two-button response pad connected to the gameport adapter of the computer. RTs were recorded to the nearest millisecond following a buttonpress.

Participants. Twelve undergraduate students, 7 females and 5 males, from the University of California participated in this experiment for partial fulfillment of a course requirement. All of the participants reported having normal or corrected-to-normal vision.

Stimuli and Procedure. The moving objects used in this and all subsequent experiments were two black squares appearing on a light gray background. The size of the objects was $0.8^{\circ}$ at a viewing distance of $57 \mathrm{~cm}$. The center fixation point, which remained visible throughout this experiment, was a smaller black square subtending $0.4^{\circ}$ in visual angle. The participants were instructed to keep their eyes on this fixation point throughout the experiment. The distance between the center of the objects and the fixation point at the start and end of the motion cycle was $4.7^{\circ}$, and the center-to-center distance of the two vertically aligned boxes was always $4.9^{\circ}$, since the trajectory of the motion was always horizontal. A small white asterisk that appeared centered in one of the two boxes served as the target stimulus and subtended $0.4^{\circ}$ of visual angle.

At the start of each trial, the two black boxes appeared vertically aligned either to the left or to the right of fixation. The side in which the two boxes could appear and the box that was cued were equally probable and were randomized across trials. After a 250-msec interval of the boxes, one of the two black boxes was cued with a brief white brightening. The cue was presented in such a way that an inner square of $0.4^{\circ}$ remained black while the rest of the object turned white for $100 \mathrm{msec}$. The objects then remained stationary for another $100 \mathrm{msec}$ before they moved (Figure 1 ).

If the boxes appeared vertically aligned to the left of fixation, the boxes moved horizontally to the right, and if the boxes appeared to the right of fixation, the boxes moved horizontally to the left. The two boxes were made to move to the left or to the right in one of two ways. In the short-range AM conditions, the boxes were displaced by half of the width of the boxes, which corresponds to a center-tocenter distance of $25 \mathrm{~min}$ of arc. The objects were displaced either toward the left or toward the right in a sequence of 20 frames from the starting point and traversed a total horizontal distance of $8.1^{\circ}$. Each 


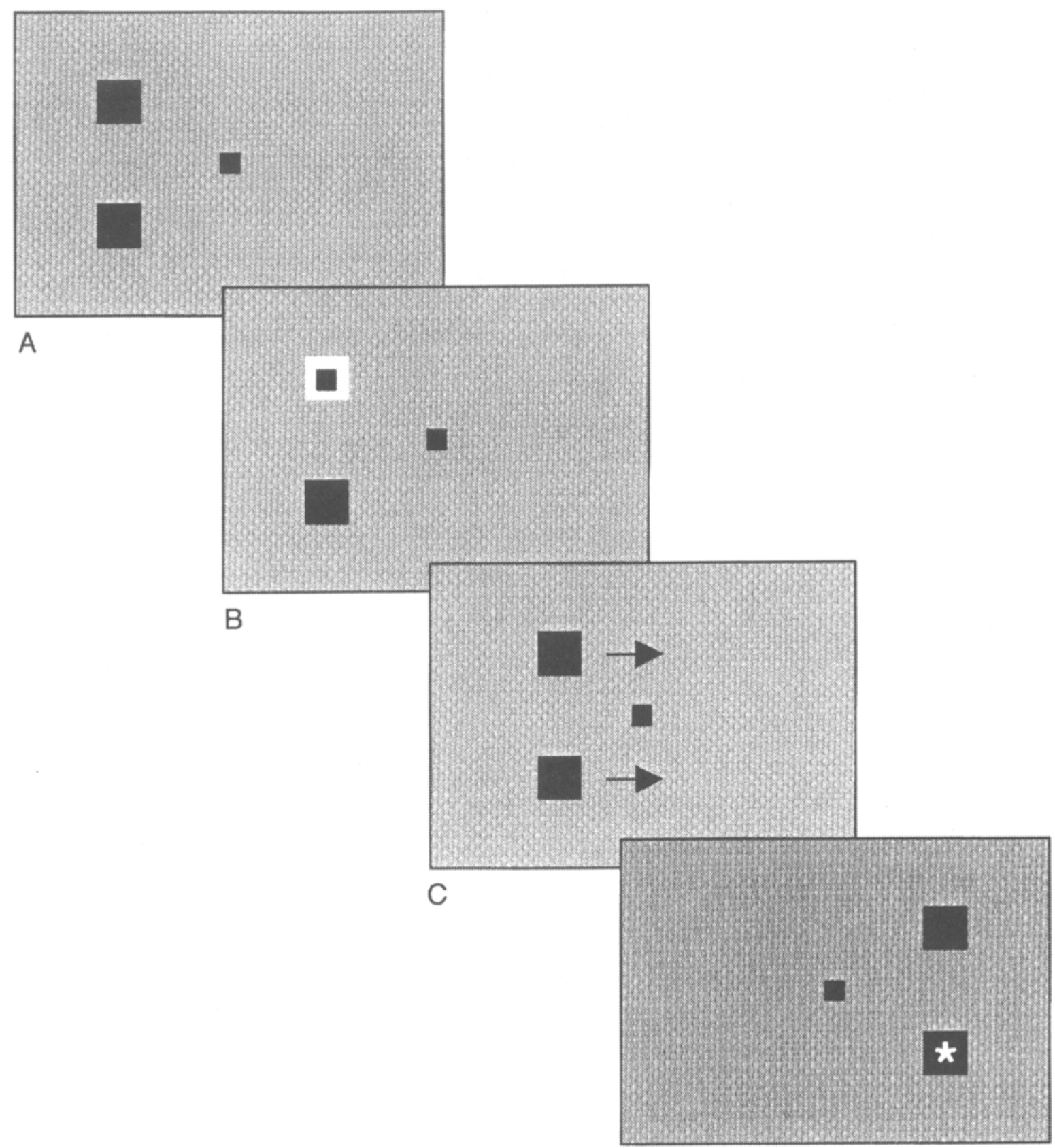

D

Figure 1. The sequence of display events on a typical trial. A: The boxes appear vertically aligned at the start of each trial either to the left or to the right of fixation for $250 \mathrm{msec}$. B: One of the two boxes is cued by a brief white brightening for $100 \mathrm{msec}$. C: The boxes begin to move simultaneously. D: After the boxes stop moving, a target appears in the previously cued or uncued object.

frame was presented for $16.7 \mathrm{msec}$ with no ISI between frames. The velocity of the motion, therefore, was $24.3 \% \mathrm{sec}$.

Under the long-range AM conditions, the two objects were made to "move" as follows: Following the offset of the peripheral cue by $100 \mathrm{msec}$, an ISI of $33.3 \mathrm{msec}$ was presented. The next frame contained the two objects spatially displaced for $33.3 \mathrm{msec}$, and then another 33.3-msec ISI was presented. The same sequence of events, ISI followed by a presentation of the displaced boxes, occurred for a total of five frames. The size of the displacement, corresponding to the center-to-center distance between two sequential frames, was $1.6^{\circ}$. The total distance of motion was again $8.1^{\circ}$, and the velocity of the motion matched that of the short-range AM condition, $24.3 \% \mathrm{sec}$. The type of motion (short or long range) the objects underwent on each trial was equally probable and randomized.

On the last frame of motion, the two boxes stopped moving and remained on the screen for $66.7 \mathrm{msec}$ before a target appeared, or remained visible for an additional $1,500 \mathrm{msec}$ without the presentation of a target (catch trials). On target-present trials, the target 
flashed either in the previously cued box or in the previously uncued box, with equal probability, for $100 \mathrm{msec}$, and the boxes then remained present until a response was made or for $1,500 \mathrm{msec}$ after the onset of the target. The cue-to-target stimulus onset asynchrony $(\mathrm{SOA})^{3}$ was $600 \mathrm{msec}$. On the catch trials, the participants were instructed to not make any response and to simply wait for the boxes to disappear. Furthermore, the participants were instructed to respond to the target stimulus as quickly and as accurately as possible by pressing a button on the response pad with their preferred hand. Target trials in which RTs were faster than $150 \mathrm{msec}$ or slower than $1,500 \mathrm{msec}$ were followed by a $500-\mathrm{msec} / 500-\mathrm{Hz}$ tone and were repeated later in the experiment. Responses made to catch trials (anticipation errors) were also signaled with the same tone and subsequently repeated in the experiment. The intertrial interval (ITI) was $2,500 \mathrm{msec}$.

Design. The experiment was run in two sessions with a practice block of 24 trials prior to the start of each session. Discounting the practice trials and trials with errors, 288 experimental trials were run on each participant. One third of these trials were catch trials. The other two thirds of the trials were target-present trials for which there was a total of eight conditions: two levels of direction of motion (left to right vs. right to left) $\times$ two levels of motion type (shortrange vs. long-range $A M) \times$ two levels of cuing (cued vs. uncued), with 24 trials in each condition. The present experiments were not designed to include direction of motion as an experimental variable, but subsequently, this within-subjects factor was added into the analyses because of a recent report demonstrating a left-to-right tracking preference (Müller \& von Mühlenen, 1996).

\section{Results and Discussion}

For trials in which no errors were made, the mean RT was calculated for each participant in each of the eight target-present conditions and analyzed with a three-way analysis of variance (ANOVA). Direction of motion, motion type, and cuing were the three within-subjects factors. The mean RTs from the correct trials and their respective standard errors of the mean ( $S E M \mathrm{~s}$ ) for each condition are presented in Table 1. The overall error rate across all participants and conditions was $0.8 \%$. Because the error rate was so low, the error data were not analyzed.

The main of effect of direction of motion was significant $[F(1,11)=5.00, p<.05]$. This was due to faster RTs when the objects moved from left to right (mean RT of $285 \mathrm{msec}$ ) than when the objects moved from right to left (mean RT of $288 \mathrm{msec}$ ). The main effect of cuing, with faster RTs to targets appearing in objects that were previously cued ( $284 \mathrm{vs.} 288 \mathrm{msec}$ ), was marginally significant $[F(1,11)=3.38, p=.09]$. The motion $\times$ cuing interaction was significant $[F(1,11)=11.96, p<.005]$.

Comparisons of cuing in the two different types of motion displays indicated that the interaction was due to the effect of cuing in the short-range AM condition (cued

Table 1

Mean Reaction Times and Standard Errors of the Mean for the Different Conditions in Experiment 1

\begin{tabular}{|c|c|c|c|c|c|c|c|c|}
\hline & \multicolumn{4}{|c|}{ Left-to-Right Motion } & \multicolumn{4}{|c|}{ Right-to-Left Motion } \\
\hline & \multicolumn{2}{|c|}{ Short Range } & \multicolumn{2}{|c|}{ Long Range } & \multicolumn{2}{|c|}{ Short Range } & \multicolumn{2}{|c|}{ Long Range } \\
\hline & RT & $S E M$ & RT & $S E M$ & RT & $S E M$ & RT & $S E M$ \\
\hline & 283.45 & 14.71 & 284.76 & 14.26 & 283.71 & 14.19 & 285.91 & 14.02 \\
\hline Uncued & 288.11 & 13.40 & 283.21 & 14.68 & 296.91 & 13.32 & 285.56 & 14.09 \\
\hline
\end{tabular}

object RT of $283 \mathrm{msec}$ vs. uncued object RT of $292 \mathrm{msec}$ ). The comparison of cuing effects in the short-range AM condition revealed a significant facilitation in the previously cued object $[t(11)=2.99, p<.025]$, whereas the comparison of cuing in the long-range AM condition indicated no difference between targets appearing in the cued versus the uncued objects (cued object RT of $285 \mathrm{msec}$ vs. uncued object RT of $284 \mathrm{msec} ; t<1$ ). Neither the main effect of motion nor any of the other interactions approached significance (all $p s>.10$ ).

The main result of the present experiment was that following an uninformative exogenous cue, a long-lasting (cue-to-target SOA of $600 \mathrm{msec}$ ) object-based facilitation of detection was present in objects that underwent short-range AM. This result, in conjunction with the recent investigation on object-based orienting in hemispheric disconnection (Tipper et al., 1997), contrasts with earlier findings that the facilitatory effect is transient (Tassinari et al., 1994) and is present only in retinotopic coordinates (Posner \& Cohen, 1984).

Also present in this experiment was a small, but significant, left-to-right tracking preference. This result is consistent with those reported by Müller and von Mühlenen (1996). In the present experiment, however, this left-to-right tracking preference occurred between groups of trials rather than within a single trial, since both objects moved together in the same direction. Another difference between the present study and the findings reported by Müller and von Mühlenen is that the participants in the present investigation only used their preferred hand to respond, which was usually the right hand. As previously mentioned, the present experiments were not designed to investigate this left-to-right tracking preference, and responding hand was not counterbalanced within or across the participants. The tracking preference found here, therefore, may be due either to a Simon-like effect (Simon, 1969), or it may be due to a general leftto-right tracking preference, as suggested by Müller and von Mühlenen. Note that, regardless of the explanation for this tracking preference, the effects of the cues in this experiment were superimposed on this left-to-right tracking preference and did not interact with it.

Although an object-based facilitation was observed in the short-range AM condition of the present experiment, there are various possible explanations for why no objectbased effect (either facilitation or IOR) was found in the long-range AM condition. One possibility is that the dissociation between short-range and long-range AM effects on reflexive orienting is of some theoretical interest insofar as it might imply different neural substrates for facilitatory and inhibitory effects. However, the differences in this experiment may be less of theoretical than of methodological importance. The dissociation may not be as informative about the neural systems involved as much as reflecting the fact that some stimulus parameters used to produce the AM may influence the degree to which the objects are tagged by attention. The fact that several laboratories (Müller \& von Mühlenen, 1996) have, for exam- 
ple, had difficulty replicating the moving IOR effect reported by Tipper and colleagues suggests that such effects may be quite vulnerable to very specific stimulus parameters. For example, with long-range AM stimuli, the ISI between the stimuli may produce a more discontinuous experience that is less easily tagged by the attentional system. In the second experiment, we sought to decrease the likelihood of object-based facilitation and thereby increase the likelihood of producing object-based IOR by summoning attention away from both moving boxes by cuing the center of the display.

\section{EXPERIMENT 2}

The previous experiment failed to demonstrate an objectbased IOR in the long-range AM condition. A number of differences exist between the previous experiment and those typically used in moving IOR studies. We slightly manipulated the procedure of this next experiment to favor the conditions that produce IOR. The initial experiment of Posner and Cohen (1984) suggested that IOR might be more robust when attention is summoned away from the cued location. Experiment 2, therefore, also included a fixation brightening following the initial cue in an attempt to optimize the conditions for producing object-based IOR.

\section{Method}

Participants. Fifteen participants, 6 females and 9 males, completed this experiment for course credit. All of the participants reported having normal or corrected-to-normal vision at the time of testing.

Stimuli and Procedure. The parameters used in this experiment were the same as those in the previous experiment except that we introduced a fixation cue at the start of the motion cycle to move attention away from the cued object and to the center fixation box. The central fixation point was cued $200 \mathrm{msec}$ after the onset of the peripheral cue, similar to the procedure used in Tipper et al. (1991; Tipper et al., 1997; Tipper et al., 1994). The fixation cue was presented by turning the entire $0.4^{\circ}$ fixation point white at the start of the motion cycle for $100 \mathrm{msec}$. The fixation point cue was offset after the sixth frame of motion in the short-range AM condition and after the second ISI prior to the presentation of the second frame in the long-range AM condition.

\section{Results and Discussion}

The overall error rate in this experiment was again very low, $0.1 \%$. The mean RTs for each participant in each condition were subjected to an ANOVA (see Table 2 for the

Table 2

Mean Reaction Times and Standard Errors of the Mean for the Different Conditions in Experiment 2

\begin{tabular}{|c|c|c|c|c|c|c|c|c|}
\hline & \multicolumn{4}{|c|}{ Left-to-Right Motion } & \multicolumn{4}{|c|}{ Right-to-Left Motion } \\
\hline & \multicolumn{2}{|c|}{ Short Range } & \multicolumn{2}{|c|}{ Long Range } & \multicolumn{2}{|c|}{ Short Range } & \multicolumn{2}{|c|}{ Long Range } \\
\hline & RT & $S E M$ & RT & $S E M$ & RT & $S E M$ & RT & $S E M$ \\
\hline $\begin{array}{l}\text { Cued } \\
\text { Uncued }\end{array}$ & $\begin{array}{l}267.53 \\
274.83\end{array}$ & $\begin{array}{r}8.74 \\
10.34\end{array}$ & $\begin{array}{l}270.42 \\
272.12\end{array}$ & $\begin{array}{r}9.71 \\
10.18\end{array}$ & $\begin{array}{l}272.42 \\
275.06\end{array}$ & $\begin{array}{c}9.84 \\
10.15\end{array}$ & $\begin{array}{l}269.50 \\
277.42\end{array}$ & $\begin{array}{l}10.29 \\
11.21\end{array}$ \\
\hline
\end{tabular}

mean RTs and $S E M$ s across participants in each condition). The main effect of cuing was significant, indicating that there was a facilitation of detection when targets appeared in the cued object ( 270 vs. $275 \mathrm{msec}$ ) regardless of the motion type $[F(1,14)=9.02, p<.01]$. This facilitation of detection was present in $80 \%$ of the participants, whereas the other $20 \%$ of the participants demonstrated a tendency for slower responses when the target appeared in the cued object. For the participants that showed facilitation, the mean RT for the cued condition was $277 \mathrm{msec}$ and the mean RT for the uncued condition was $284 \mathrm{msec}$. The mean RTs for the participants that did not show facilitation were $241 \mathrm{msec}$ for the cued-object condition and $238 \mathrm{msec}$ for the uncued condition. None of the other main effects nor interactions approached significance (all $p s>.10$ ).

No left-to-right tracking preference was observed in this experiment. This may be due to the central fixation cue pulling attention away from the tracked moving objects. Consistent with this interpretation, Müller and von Mühlenen (1996) also found that attentive left-to-right tracking was reduced when the timing parameters of the central fixation cue were similar to those used in this study. As in Experiment 1, an object-based facilitation was observed in this experiment even though some of the parameters (uninformative exogenous cue, reasonably long cue-to-target SOA, and a fixation cue to move attention away from a cued object) were manipulated to favor the production of IOR.

In contrast to the findings of the previous experiment, facilitation was associated with both short- and long-range $A M$ in the present experiment. Although these results show that the object-based facilitatory effect is generalizable with regard to the features of stimuli that it can track, nevertheless it was clear that we needed to search elsewhere for a manipulation that could dissect object-based facilitation and object-based IOR. In the next experiment a different manipulation that might favor the production of IOR was employed: The cue-to-target SOA was lengthened by $300 \mathrm{msec}$ to determine whether an object-based IOR would be present at this longer interval.

\section{EXPERIMENT 3}

This experiment used a longer cue-to-target SOA in an attempt to favor conditions more conducive to producing object-based IOR. Furthermore, a discrimination as well as a simple detection task was used. Tanaka and Shimojo (1996) and Egly et al. (in press) have recently shown that under conditions that produce an IOR at long cue-to-target intervals in a simple detection task, the same conditions produce a facilitatory effect when an identity discrimination is required. On the basis of these recent studies, we expected an object-based IOR for the detection task, if our manipulations were suitable to reveal one, and an object-based facilitation under the discrimination tasks. No fixation point cue was used in this experiment. 


\section{Method}

Participants. Sixteen students participated in this experiment. Eleven of the participants were females and 5 were males. All of the participants reported having normal or corrected-to-normal vision and were paid for participating.

Stimuli and Procedure. The stimuli and procedures were similar to those employed in the previous two experiments. The changes made for this experiment were as follows. The center fixation point, which remained visible throughout the experiment, was a plus sign that subtended $0.2^{\circ}$ horizontally and vertically and was never cued. The target in this experiment was a white $\mathrm{X}$ or $\mathrm{O}$ that appeared centered in one of the two boxes. The size of the letters both subtended $0.4^{\circ}$ of visual angle. The participants' eye movements were monitored with a Pulnix camera connected to a monitor that displayed the position of the eyes. The participants were reminded to fixate on the cross whenever eye movements were detected, which was a rare event.

The SOA was lengthened between the cue and target in this experiment by slowing the motion of the objects. In the short-range AM conditions, each frame was presented for $33 \mathrm{msec}$ with no ISI between frames. The velocity of the motion, therefore, was $12.15 \% \mathrm{sec}$ (half the velocity used in the previous experiments). Under the longrange AM conditions, the two boxes remained on the screen for $67 \mathrm{msec}$, and the ISIs between frames were also $67 \mathrm{msec}$. The velocity of the motion matched that of the short-range AM condition, $12.15 \%$ sec.

On the last frame of motion, the two boxes stopped moving and remained on the screen for $33 \mathrm{msec}$ before a target appeared, or remained visible for an additional $1,500 \mathrm{msec}$ without the presentation of a target (catch trials). In the discrimination task, either the target $\mathrm{X}$ or the target $\mathrm{O}$ appeared centered in one of the two boxes. In the detection task, the target was only an $\mathrm{X}$ or only an $\mathrm{O}$ in any given block. The target appeared centered in one of the two objects and remained present until a response was made or for $1,500 \mathrm{msec}$ after the onset of the target, at which point the computer generated a beep. The cue-to-target SOA was $900 \mathrm{msec}$ and the ITI was $2,500 \mathrm{msec}$.

Discounting the practice trials, each participant completed 288 trials for the detection task and 288 trials for the discrimination task. Half of the participants ran in the detection task first and the other half on the discrimination task first. Furthermore, in the detection task, half of the participants were run with the $\mathrm{X}$ as the target first, and the other half were run first with an $\mathrm{O}$ with a short break between blocks. The participants were given one short break during the discrimination task. Twenty-four practice trials were given before each of the two blocks in the detection task. For the discrimination task, a practice block consisting of 48 trials was administered before the start of the discrimination block.

For both detection and discrimination tasks, one third of the trials were catch trials in which no target was presented. On these catch trials, the participants were instructed to not make any response and to simply wait for the boxes to disappear. On the other two thirds of the trials, a target appeared either in the previously cued box or in the previously uncued box. For the detection task, the participants responded by pressing only the left button with their preferred hand for the $O$ target block and only the right button with their preferred hand for the $\mathrm{X}$ target block. In the discrimination task, either an $\mathrm{X}$ or an $\mathrm{O}$ could appear and the participants were instructed to press the left button if the target was an $O$ or the right button if the target was an $\mathrm{X}$. Both responses in the discrimination task were made with the index and middle fingers of the preferred hand. The probability of the target appearing in the cued or uncued box on the target-present trials was equal. In addition, in the discrimination task, the probability of the target being either an $\mathrm{X}$ or an $\mathrm{O}$ was equal.

The participants were instructed to respond to the target stimulus as quickly and accurately as possible. As in the previous two experiments, target trials in which RTs were faster than $150 \mathrm{msec}$ or in which no response was made by $1,500 \mathrm{msec}$ after the onset of the target were followed by a 500 -msec tone and were repeated later in the experiment. In addition, incorrect responses to the targets in the discrimination task were followed by the beep and were subsequently repeated in the experiment. Responses made to catch trials were scored as anticipation errors and were repeated later in the experiment. Excluding the practice and catch trials, there were 24 trials for each of the 16 conditions. The four within-subjects factors were task (detection vs. discrimination) $\times$ direction of motion (left to right vs. right to left) $\times$ motion type (short-range AM vs. longrange $A M) \times$ cuing (cued vs. uncued).

\section{Results and Discussion}

Errors in the detection task constituted $0.2 \%$ of the trials. The overall error rate in the discrimination task was $2.1 \%$ of the trials and was not further analyzed. Mean RT was calculated for the correct responses of each participant in each condition. An ANOVA with task, direction of motion, motion type, and cuing as the four withinsubject variables was conducted. The main effect of task, with faster RTs in the detection task (301 msec vs. discrimination task RT of $504 \mathrm{msec}$ ), was significant $[F(1,15)$ $=256.49, p<.001]$. A marginally significant effect of direction of motion was obtained $[F(1,15)=3.55, p=$ $.076]$. This was due to faster responses when the objects moved from the left to the right (399 vs. $406 \mathrm{msec}$ in the right-to-left conditions). The only other effect that achieved significance was the main effect of cuing $[F(1,15)=5.06$, $p<.05]$. This, again, was based on faster responses when the targets appeared in the previously cued object $(400 \mathrm{msec})$ rather than the uncued object $(405 \mathrm{msec})$. In this experiment, $75 \%$ of the participants showed this facilitation of detection for targets appearing in previously cued objects. The mean RTs for the participants showing facilitation of detection were 386 and $395 \mathrm{msec}$ for targets appearing in the cued and the uncued object, respectively. For the participants with slower responses to targets in cued objects, the mean RTs were $441 \mathrm{msec}$ for the cued-object condition and $434 \mathrm{msec}$ for the uncuedobject condition. The main effect of motion type and all of the interactions did not approach significance (all $p s>$ .10). See Table 3 for the averaged data in each condition.

The results of this experiment show that a facilitation of both detection and discrimination from an uninformative peripheral event can exist at intervals of up to $900 \mathrm{msec}$ after cue onset. They replicate the observations of facilitation of detection and extend the findings of the earlier experiments to also show facilitation of discrimination speed. Furthermore, the left-to-right tracking bias, although only marginally significant, was again observed. It still remains a puzzle as to why an objectbased IOR has not been observed thus far in these experiments. Perhaps the fixation cue that we employed in Experiment 2 was too subtle and inefficient to drive attention back to fixation. The next experiment manipulated the time of onset of the fixation cue to more effectively bring attention back to fixation in an attempt to reveal an object-based IOR. 
Table 3

\begin{tabular}{|c|c|c|c|c|c|c|c|c|}
\hline \multicolumn{9}{|c|}{$\begin{array}{l}\text { Mean Reaction Times and Standard Errors of the Mean } \\
\text { for the Different Conditions in Experiment } 3\end{array}$} \\
\hline & \multicolumn{4}{|c|}{ Left-to-Right Motion } & \multicolumn{4}{|c|}{ Right-to-Left Motion } \\
\hline & \multicolumn{2}{|c|}{ Short Range } & \multicolumn{2}{|c|}{ Long Range } & \multicolumn{2}{|c|}{ Short Range } & \multicolumn{2}{|c|}{ Long Range } \\
\hline & RT & $S E M$ & RT & $S E M$ & RT & $S E M$ & $\mathrm{RT}$ & $S E M$ \\
\hline \multicolumn{9}{|l|}{ Detection } \\
\hline Cued & 296.19 & 12.25 & 299.93 & 13.65 & 300.38 & 14.72 & 301.24 & 13.53 \\
\hline Uncued & 299.86 & 13.10 & 299.41 & 14.08 & 307.16 & 12.81 & 303.44 & 15.68 \\
\hline \multicolumn{9}{|c|}{ Discrimination } \\
\hline Cued & 494.93 & 17.24 & 498.52 & 18.74 & 502.51 & 16.43 & 504.54 & 13.72 \\
\hline Uncued & 501.38 & 15.96 & 503.26 & 15.91 & 516.33 & 14.82 & 509.24 & 13.34 \\
\hline
\end{tabular}

\section{EXPERIMENT 4}

It is possible that an object-based IOR was present in the previous experiments but was not revealed because the conditions that were employed still favored an objectbased facilitation of detection. It has been shown that the introduction of a fixation cue following a peripheral exogenous cue can reveal IOR in a discrimination task shown to produce a facilitation of detection when no fixation cue was used (Egly et al., in press). It may be that the fixation cue used in Experiment 2 was not effective in bringing attention away from the moving boxes, which may have been particularly salient and attention grabbing due to the motion that the boxes were undergoing. In this experiment, the fixation point was cued after the boxes stopped moving, so the motion of the objects themselves could not dampen the effects of the fixation cue.

\section{Method}

Participants. Eighteen undergraduate students, 10 females and 8 males, participated in this experiment for course credit. All reported having normal or corrected-to-normal vision at the time of testing.

Stimuli and Procedure. Only a detection task was used in this experiment. The parameters were almost identical to those in the first two experiments. The only change in this experiment was that we cued the fixation point $100 \mathrm{msec}$ after the boxes stopped moving rather than during the motion of the two boxes. The fixation cue was again presented by turning the entire $0.4^{\circ}$ fixation point white for $100 \mathrm{msec}$. Following the fixation cue, the boxes remained present for another $166.7 \mathrm{msec}$ before a target appeared or for another $1,666.7 \mathrm{msec}$ for the catch trials. This produced a cue-to-target SOA of $900 \mathrm{msec}$ on the target-present trials. The ITI was $2,500 \mathrm{msec}$.

\section{Results and Discussion}

The mean RTs for trials in which no errors were made were calculated for each participant in each of the eight target-present conditions and subjected to an ANOVA.

Table 4

Mean Reaction Times and Standard Errors of the Mean for the Different Conditions in Experiment 4

\begin{tabular}{|c|c|c|c|c|c|c|c|c|}
\hline & \multicolumn{4}{|c|}{ Left-to-Right Motion } & \multicolumn{4}{|c|}{ Right-to-Left Motion } \\
\hline & \multicolumn{2}{|c|}{ Short Range } & \multicolumn{2}{|c|}{ Long Range } & \multicolumn{2}{|c|}{ Short Range } & \multicolumn{2}{|c|}{ Long Range } \\
\hline & $\mathrm{RT}$ & $S E M$ & RT & $S E M$ & RT & $S E M$ & RT & $S E M$ \\
\hline Cued & 294.25 & 15.60 & 285.38 & 15.34 & 296.43 & 15.57 & 294.16 & 15.53 \\
\hline Uncued & 287.91 & 15.57 & 284.97 & 14.88 & 292.33 & 15.68 & 285.52 & 16.30 \\
\hline
\end{tabular}

The mean RTs and SEMs across participants for each condition are shown in Table 4. Direction of motion, motion type, and cuing were the three within-subjects factors. The overall error rate across all participants and conditions in this experiment was $0.6 \%$. The error data were not further analyzed.

The main effect of direction of motion was again marginally significant $[F(1,17)=3.74, p=.067]$. This marginally significant effect was again due to faster responses when the objects moved from left to right $(288 \mathrm{msec})$ and slower responses when the objects moved from right to left $(292 \mathrm{msec})$. The effect of motion type achieved significance in this experiment, with overall faster responses in the long-range AM condition (mean RT of $288 \mathrm{msec}$ in the long-range AM condition and mean RT of $293 \mathrm{msec}$ in the short-range AM condition) $[F(1,17)=18.30, p<.001]$. The main effect of cuing was also significant $[F(1,17)=4.60, p<.05]$, now reflecting an object-based IOR with slower RTs to targets appearing in previously cued objects (cued RT of 293 vs. uncued RT of $288 \mathrm{msec}$ ). Fourteen of the 18 participants $(78 \%)$ demonstrated this slowing to targets in previously cued objects. The mean RTs for the cued and uncued conditions for these 14 participants showing object-based IOR were 283 and $275 \mathrm{msec}$, respectively. For the remaining 4 participants, the mean RT for the cued-object condition was $326 \mathrm{msec}$ and the mean RT for the uncued object condition was $332 \mathrm{msec}$. None of the interactions were significant (all $p s>.10$ ).

In this experiment, object-based IOR may have been manifest because the fixation point cue was more effective in reorienting attention away from the cued object after it stopped moving. The present results confirm the findings of Tipper et al. (1991; Tipper et al., 1997; Tipper et al., 1994) that exogenous cues can produce object-based IOR. They extend Tipper's results by showing that objectbased IOR can occur with translational as well as rotational motion and that object-based IOR can track objects that undergo either short- or long-range AM. Together with the results of our experiments showing that facilitation can occur with both short- and long-range AM, we conclude that the short-range/long-range AM dichotomy is not diagnostic in dissecting these orienting effects.

Because the manipulation of cuing the fixation point after the boxes stopped moving not only changed the 
Table 5

Mean Reaction Times and Standard Errors of the Mean for the Different Conditions in Experiment 5

\begin{tabular}{|c|c|c|c|c|c|c|c|c|}
\hline & \multicolumn{4}{|c|}{ Left-to-Right Motion } & \multicolumn{4}{|c|}{ Right-to-Left Motion } \\
\hline & \multicolumn{2}{|c|}{ Fixation Cued } & \multicolumn{2}{|c|}{ Fixation Offset } & \multicolumn{2}{|c|}{ Fixation Cued } & \multicolumn{2}{|c|}{ Fixation Offset } \\
\hline & RT & $S E M$ & RT & $S E M$ & RT & $S E M$ & RT & $S E M$ \\
\hline Cued & 282.71 & 8.38 & 299.27 & 9.42 & 289.55 & 10.82 & 305.31 & 11.31 \\
\hline Uncued & 280.60 & 9.22 & 293.74 & 8.48 & 284.21 & 8.59 & 294.60 & 7.97 \\
\hline
\end{tabular}

possible effectiveness of the fixation cue but also the cueto-target SOA, it is unclear which of these two manipulations shifted the results from facilitation to IOR. However, in Experiment 3, a cue-to-target SOA of $900 \mathrm{msec}$ was also used and yet an object-based facilitation was observed. This suggests that the shift in results observed in this experiment was most likely due to the manipulation of the fixation point. The remaining experiments changed other properties of the fixation point to further favor the conditions of obtaining an object-based IOR.

\section{EXPERIMENT 5}

The present experiment was conducted in two separate blocks. Both blocks employed a larger fixation point. In one block, the larger fixation point was cued at the onset of the motion cycle. In the other block, the fixation point was offset $200 \mathrm{msec}$ prior to the onset of the peripheral cue. Abrams and Dobkin (1994a) have shown that when the fixation point is offset prior to target onset, IOR measured through saccadic eye movement latencies in a static display is enhanced. They suggested that the interactive effects of fixation offset and IOR on saccade latency may have been due to the generation of these effects both occurring in the superior colliculus. The current changes in the fixation point cuing procedure were made to determine whether other manipulations of fixation would also favor object-based IOR. Although our manipulations of fixation offset differed from those used by Abrams and Dobkin, we reasoned that an offset prior to the cue (in contrast to before the target, as in their experiment) may also result in an increase of IOR.

\section{Method}

Participants. Fifteen University of California undergraduate students, 9 females and 6 males, participated in this experiment for course credit. All had normal or corrected-to-normal vision at the time of testing.

Stimuli and Procedure. The stimuli and procedures in this experiment were identical to those used in Experiments 1, 2, and 4 with the exception of the following few changes. First, the two boxes were displaced further peripherally so that the distance between the two boxes equaled the total distance of the motion trajectory. ${ }^{4}$ The center-to-center distance of the two boxes was now always $8.1^{\circ}$, and the distance between the two boxes and the center fixation box at the start and end of the motion cycle was $5.7^{\circ}$. The total distance of the motion trajectory was still $8.1^{\circ}$, as in the previous experiments. The fixation point was also changed. The fixation point was now the same size, $0.8^{\circ}$, as the two objects that moved. In addition, the cue-to-target SOA in this experiment was $600 \mathrm{msec}$, as in the first two experiments.

Each participant completed two blocks for this experiment. In one block, the fixation point was cued in the same manner in which the peripheral box was cued. An inner square of $0.4^{\circ}$ remained black while the rest of the fixation point turned white for $100 \mathrm{msec}$. In the other block, the fixation point was offset $200 \mathrm{msec}$ prior to the onset of the peripheral cue and remained off until a response was made. The order of blocks was counterbalanced between participants. The final change that was made in this experiment was that only the short-range AM conditions were used.

\section{Results and Discussion}

The overall error rate for this experiment was $1.2 \%$. The error data were not further analyzed. The mean RTs were calculated for each participant in each condition and subjected to an ANOVA (see Table 5 for the mean RTs across the participants in each condition). Direction of motion, fixation cue type, and cuing were the three within-subjects variables. There was again a marginally significant main effect of direction of motion $[F(1,14)=$ $4.05, p=.061]$, reflecting faster RTs in the left-to-right motion conditions ( $289 \mathrm{vs} .293 \mathrm{msec}$ in the right-to-left condition). The main effect of fixation type was also marginally significant $[F(1,14)=3.15, p=.095]$. Subjects tended to respond faster when the fixation point remained on and was cued during the motion cycle ( 284 vs. $298 \mathrm{msec}$ ). Finally, there was a significant main effect of cuing, reflecting an object-based IOR $[F(1,14)=$ $8.03, p<.02]$. The mean RT for targets appearing in previously cued objects was $294 \mathrm{msec}$, and the mean RT for targets appearing in previously uncued objects was $288 \mathrm{msec}$. Of the $73 \%$ of the participants showing this object-based IOR, the mean RT for the cued-object condition was 300 msec and the mean RT for the uncuedobject condition was $291 \mathrm{msec}$. For the remaining $27 \%$ of participants who showed speeding up of responses to targets in previously cued objects, the mean RTs for the cued and uncued conditions were 277 and $282 \mathrm{msec}$, respectively. None of the interactions approached significance (all $p s>.10$ ).

Experiment 5 demonstrated again that object-based IOR can be manifest under conditions of short-range AM. The results show that object-based IOR can be found under a wider range of conditions than reported heretofore. Although an object-based IOR was again observed in this experiment, the magnitude of the facilitatory and inhibitory effects reported thus far were small (between 
4 and $9 \mathrm{msec}$ ). One more experiment was conducted to replicate the object-based IOR effect.

\section{EXPERIMENT 6}

This experiment was similar to the previous one, but a different fixation-point condition was used. The main purpose of this experiment was to replicate the results of the previous experiment with a slight manipulation. In this experiment, two fixation-point conditions were used. One condition was identical to the fixation-cued condition in the previous experiment. The other condition used the same large fixation point as in the previous experiment, but was neither offset nor cued.

\section{Method}

Participants. Eighteen University of California undergraduate students, 11 females and 7 males, participated in this experiment for course credit. All had normal or corrected-to-normal vision at the time of testing.

Stimuli and Procedure. The stimuli and procedures in this experiment were similar to those used in the previous experiment. In this experiment, however, the fixation point remained on but was not cued on half of the trials. The other half of the trials were identical to those in the previous experiment, in which the fixation point was cued. The two fixation-point conditions in this experiment were randomly intermixed.

\section{Results and Discussion}

Errors constituted $0.4 \%$ of all trials and were not further analyzed. Mean RTs were calculated for the remaining trials in each of the conditions for each participant (see Table 6). The data were subjected to an ANOVA with three within-subjects factors: direction of motion, fixation cue type, and cuing. There was a significant main effect of direction of motion $[F(1,17)=8.74, p<.01]$, reflecting faster RTs in the left-to-right motion conditions ( $286 \mathrm{vs.}$ $292 \mathrm{msec}$ in the right-to-left condition). The main effect of fixation type was also significant $[F(1,17)=17.21, p<$ $.001]$ as a result of participants responding faster when the fixation point was cued during the motion cycle ( $284 \mathrm{vs.}$ $294 \mathrm{msec}$ ). Finally, there was a significant main effect of cuing, reflecting an object-based IOR [ $292 \mathrm{msec}$ cued RT vs. $287 \mathrm{msec}$ uncued RT; $F(1,17)=5.53, p<.05]$. None of the interactions were significant (all $p s>.10$ ). This experiment replicated the object-based IOR effects reported in the previous two experiments. Furthermore, the left-toright tracking preference reported by Müller and von Mühlenen (1996) was also replicated.

\section{GENERAL DISCUSSION}

The major new finding of the present investigation is that following an uninformative exogenous cue, an objectbased facilitatory effect can be measured for several hundred milliseconds after the cue. This facilitatory effect can influence detection and discrimination, it may be object based, and it is not necessarily retinotopic as originally suggested by Posner and Cohen (1984). Also in this investigation, we have replicated the object-based IOR effect reported by Tipper and his colleagues (Tipper et al., 1991; Tipper et al., 1997; Tipper et al., 1994). Furthermore, the left-to-right tracking bias reported by Müller and von Mühlenen (1996) was also replicated.

It has previously been shown that location-based IOR can delay manual response latencies, that it can influence saccadic latency and direction, and that it can also influence temporal order judgments (Gibson \& Egeth, 1994; Rafal, Calabresi, Brennan, \& Sciolto, 1989; Rafal et al., 1994). Furthermore, Tassinari et al. (1994) have shown that inhibition can be present at cue-to-target SOAs as small as $0 \mathrm{msec}$ - that is, as early as simultaneous presentations of cue and target. Tassinari et al. interpreted these findings to suggest that the inhibitory effect is the dominant effect of visual orienting. They further suggested that the facilitatory and inhibitory effects of orienting are separate and independent mechanisms overlapping in space and time and that the facilitatory effect is a transient phenomenon that is present only under specific conditions. In contrast to the proposal by Tassinari et al., the present results show that the facilitatory effect can be sustained for several hundred milliseconds (Table 7).

An object-based facilitatory effect following uninformative exogenous cues has also been reported in two other studies. Tipper et al. (1997) found an object-based facilitation of detection in split-brain patients when cued objects crossed from one hemifield into another. On trials within the same block, cued objects that moved within a hemifield, and therefore needing no callosal transfer to maintain their representations, exhibited object-based IOR. From these results, Tipper et al. concluded that this object-based facilitatory effect was subcortically mediated, whereas the object-based IOR was cortically mediated. They suggested that a cue activated both a facilitatory and inhibitory tag that could track an object. Another experiment also revealed an object-based facilitatory effect with moving stimuli and eye-movement latencies as the dependent measure (Abrams \& Dobkin, 1994b). In

Table 6

Mean Reaction Times and Standard Errors of the Mean for the Different Conditions in Experiment 6

\begin{tabular}{|c|c|c|c|c|c|c|c|c|}
\hline & \multicolumn{4}{|c|}{ Left-to-Right Motion } & \multicolumn{4}{|c|}{ Right-to-Left Motion } \\
\hline & \multicolumn{2}{|c|}{ Fixation Cued } & \multicolumn{2}{|c|}{ No Fixation Cue } & \multicolumn{2}{|c|}{ Fixation Cued } & \multicolumn{2}{|c|}{ No Fixation Cue } \\
\hline & RT & $S E M$ & RT & $S E M$ & RT & $S E M$ & RT & $S E M$ \\
\hline Cued & 282.52 & 9.88 & 294.83 & 11.23 & 291.39 & 10.78 & 299.67 & 11.72 \\
\hline
\end{tabular}


Table 7

Summary of the Experimental Variables and Results for Each Experiment

\begin{tabular}{|c|c|c|c|c|c|}
\hline & Fixation Size & Motion Type & Fixation Manipulation & SOA & Main Result \\
\hline Experiment 1 & Small & $\begin{array}{l}\text { Short range and } \\
\text { long range }\end{array}$ & Not cued & 600 & Facilitation \\
\hline Experiment 2 & Small & $\begin{array}{l}\text { Short range and } \\
\text { long range }\end{array}$ & Cued at start of motion & 600 & Facilitation \\
\hline Experiment 3 & Small & $\begin{array}{l}\text { Short range and } \\
\text { long range }\end{array}$ & Not cued & 900 & Facilitation \\
\hline Experiment 4 & Small & $\begin{array}{l}\text { Short range and } \\
\text { long range }\end{array}$ & Cued after boxes stop & 900 & IOR \\
\hline Experiment 5 & Large & Short range & $\begin{array}{l}\text { Larger and offset or } \\
\text { cued at start of motion }\end{array}$ & 600 & IOR \\
\hline Experiment 6 & Large & Short range & $\begin{array}{l}\text { Larger and no cue or } \\
\text { cued at start of motion }\end{array}$ & 600 & IOR \\
\hline
\end{tabular}

Note-SOA, stimulus onset asynchrony (in milliseconds). IOR, inhibition of return.

their subsequent experiments, however, Abrams and Dobkin replicated the object-based IOR with eye-movement latencies and did not emphasize the importance of the object-based facilitatory effect.

Kahneman, Treisman, and Gibbs (1992) have also shown object-specific preview effects in moving objects in a different attentional procedure. In their series of experiments using a priming rather than a cuing paradigm, participants were faster to name a letter when it appeared in the same object in which it had been previously presented. An object-based facilitation effect has also been observed in normals and patients after orienting to predictive cues (Egly, Driver, \& Rafal, 1994; Egly, Rafal, Driver, \& Starrveldt, 1994). The studies by Egly et al., however, used static displays, and the objects defined by shape were perhaps represented at a different level than the objects defined by motion in this study. Regardless of the level of an objectbased representation, the results of the present experiments in normals demonstrate that a facilitatory effect can persist for several hundred milliseconds following uninformative exogenous cues and that the facilitatory tag can stay with an "object" as it moves through space.

Although the present experiments do not prove that both facilitation and IOR are generated concurrently in the same object, the results are consistent with this interpretation and also with an account proposed by Tipper et al. (1997). These results are consistent with the proposal that both facilitation and IOR are activated by a luminance change, and that the net result observed on detection RT may depend on the specific parameters that favor one orienting process over the other. This coexistence account of these two orienting processes perhaps explains the small effect sizes observed here, since both a facilitatory and an inhibitory effect of orienting may have had competing effects on performance. They also converge with other results that provide evidence for the coexistence of facilitation and inhibition (Egly et al., in press; Gibson \& Egeth, 1994; Rafal et al., 1994; Rafal \& Henik, 1994; Tanaka \& Shimojo, 1996; Tassinari et al., 1994; Tipper et al., 1997).

Although a coexistence explanation can account for the experimental fragility in measuring an object-based
IOR, it may be that object-based IOR is inconsistent because of practice effects (Weaver, Lupiáñez, \& Watson, 1998). Weaver et al. showed that the amount of practice a participant receives is inversely related to the magnitude of IOR (both location based and object based). Since the amount of practice administered in the present investigation was small, practice effects cannot account for the presence of object-based facilitation and the absence of object-based IOR in the first three experiments. However, it is likely that amount of practice was the cause of Müller and von Mühlenen's (1996) failure to replicate.

Other factors might also favor object-based facilitation instead of object-based IOR. Because most of the manipulations that shifted the results from facilitation to inhibition in our experiments were changes of the fixation point, it is possible that the fixation stimulus needs to be salient enough to draw attention away from the cued object in order for object-based IOR to be manifest. This account explains the differences in results between the first three experiments and Experiment 4, in which the fixation point was cued at a time when no other events were occurring. It also explains the differences in results between the experiments in which a small fixation point was used and object-based facilitation was observed and Experiments 5 and 6, in which a larger, more salient fixation point was used and object-based IOR was the result. This salient fixation account, however, does not address the result of the object-based IOR observed in the condition of Experiment 5 in which the fixation point was removed prior to the onset of the peripheral exogenous cue. This offset manipulation, however, may have generated a more robust IOR to begin with (Abrams \& Dobkin, 1994a) and may therefore have resulted in an object-based IOR. It may be suggested tentatively that any manipulations that increase the robustness of locationbased IOR, such as the use of a fixation cue or offsetting the fixation point prior to target onset, also increases the likelihood of generating an object-based IOR.

In conclusion, we have shown that object-based facilitation as well as object-based IOR may both be manifest at long cue-to-target intervals. Certain manipulations of the experimental parameters, such as effectively bring- 
ing attention back to fixation after a peripheral cue, may increase the likelihood of producing one effect over the other. Furthermore, the recently reported left-to-right tracking preference (Müller \& von Mühlenen, 1996) has also been demonstrated in the present experiments in addition to the component effects of reflexive visual orienting of attention. Interpretations of this left-to-right tracking bias from the present series of investigations must be made with caution, however, since these experiments were not designed to investigate this issue and response hand was not controlled. At present, the boundary conditions that produce object-based facilitation and those that favor object-based IOR remain to be defined.

\section{REFERENCES}

Abrams, R. A., \& Dobkin, R. S. (1994a). The gap effect and inhibition of return: Interactive effects on eye movement latencies. Experimental Brain Research, 98, 483-487.

ABRAMS, R. A., \& DobKIN, R. S. (1994b). Inhibition of return: Effects of attentional cuing on eye movement latencies. Journal of Experimental Psychology: Human Perception \& Performance, 20, 467-477.

BRADDICK, O. (1974). A short-range process in apparent motion. Vision Research, 14, 519-527.

Cavanagh, P., \& Mather, G. (1989). Motion: The long and short of it. Spatial Vision, 4, 103-129.

Chang, J. J., \& Julesz, B. (1983). Displacement limits, directional anisotropy and direction versus form discrimination in random-dot cinematograms. Vision Research, 23, 639-646.

Dick, M., Ullman, S., \& SAGi, D. (1987). Parallel and serial processes in motion detection. Science, 237, 400-402.

EGLY, R., DRIVER, J., \& RAFAl, R. D. (1994). Shifting visual attention between objects and locations: Evidence from normal and parietal lesion subjects. Journal of Experimental Psychology: General, 123, 161-177.

Egly, R., Rafal, R. D., Driver, J., \& Starrveldt, Y. (1994). Covert orienting in the split brain reveals hemispheric specialization for objectbased attention. Psychological Science, 5, 380-383.

EgLY, R., RAFAL, R. D., HeNIK, A., \& Berger, A. (in press). Reflexive and voluntary covert orienting in detection and discrimination tasks. Journal of Experimental Psychology: Human Perception \& Performance.

GIBSON, B. S., \& EGETH, H. (1994). Inhibition and disinhibition of return: Evidence from temporal order judgments. Perception \& Psychophysics, 56, 669-680.

Horowitz, T., \& Treisman, A. (1994). Attention and apparent motion. [Special issue: In honor of Bela Julesz: II. Texture and visual search]. Spatial Vision, 8, 193-219.

IVRY, R. B., \& COHEN, A. (1990). Dissociation of short- and long-range apparent motion in visual search. Journal of Experimental Psychology: Human Perception \& Performance, 16, 317-331.

Kahneman, D., Treisman, A., \& Gibbs, B. J. (1992). The reviewing of object files: Object-specific integration of information. Cognitive Psychology, 24, 175-219.

Mack, A., Tang, B., Rock, I., Stone, W., Linnett, C. M., \& Ro, T. (1991, November). Apparent motion and attention. Paper presented at the annual meeting of the Psychonomic Society, San Francisco.

MAYLOR, E. A. (1985). Facilitatory and inhibitory components of orienting in visual space. In M. I. Posner \& O. S. M. Marin (Eds.), Attention and performance $X I$ (pp. 189-204). Hillsdale, NJ: Erlbaum.

MAYLOR, E. A., \& HoCKEY, R. (1985). Inhibitory component of externally controlled covert orienting in visual space. Journal of Experimental Psychology: Human Perception \& Performance, 11, 777-787.

Mikami, A. (1991). Direction selective neurons respond to short-range and long-range apparent motion stimuli in macaque visual area MT. International Journal of Neumscience, 61, 101-112.

Müller, H. J., \& VON MÜHLENEN, A. (1996). Attentional tracking and inhibition of return in dynamic displays. Perception \& Psychophysics, 58, 224-249.
PETERSIK, J. T. (1989). The two-process distinction in apparent motion. Psychological Bulletin, 106, 107-127.

PosNer, M. I., \& COHEN, Y. (1984). Components of visual orienting. In H. Bouma \& D. G. Bouwhuis (Eds.), Attention and performance X: Control of language processes (pp. 531-556). Hillsdale, NJ: Erlbaum.

Rafal, R. D., Calabresi, P., Brennan, C., \& Sciolto, T. (1989). Saccade preparation inhibits reorienting to recently attended locations. Journal of Experimental Psychology: Human Perception \& Performance, 15, 673-685.

RAFAL, R. D., EgLx, R., \& RHODES, D. (1994). Effects of inhibition of return on voluntary and visually guided saccades. Canadian Journal of Experimental Psychology, 48, 284-300.

Rafal, R. [D.], \& HeNIK, A. (1994). The neurology of inhibition: Integrating controlled and automatic processes. In D. Dagenbach \& T. H. Carr (Eds.), Inhibitory processes in attention, memory, and language (pp. 1-51). San Diego: Academic Press.

RocK, I. (1983). The logic of perception. Cambridge, MA: MIT Press.

SIMON, J. R. (1969). Reactions toward the source of stimulation. Journal of Experimental Psychology, 81, 174-176.

TANaKA, Y., \& SHImojo, S. (1996). Location vs feature: Reaction time reveals dissociation between two visual functions. Vision Research, 36, 2125-2140.

Tassinari, G., Aglioti, S., Chelazzi, L., Peru, A., \& Berlucchi, G. (1994). Do peripheral non-informative cues induce early facilitation of target detection? Vision Research, 34, 179-189.

TIPPER, S. P., DrIvER, J., \& WEAVER, B. (1991). Object-centred inhibition of return of visual attention. Quarterly Journal of Experimental Psychology, 43A, 289-298.

Tipper, S. P., Rafal, R. D., Reuter-Lorenz, P., Starkveldt, Y., Ro, T., Egly, R., Danziger, S., \& Weaver, B. (1997). Object-based facilitation and inhibition from visual orienting in the human split-brain. Journal of Experimental Psychology: Human Perception \& Performance, 23, 1522-1532.

Tipper, S. P., Weaver, B., Jerreat, L. M., \& Burak, A. L. (1994). Object- and environment-based inhibition of return of visual attention. Journal of Experimental Psychology: Human Perception \& Performance, 20, 478-499.

WEAVER, B., Lupiáñez, J., \& WATSON, F. L. (1998). The effects of practice on object-based, location-based, and static-display inhibition of return. Perception \& Psychophysics, 60, 993-1003.

\section{NOTES}

1. Although there have been differences in opinion over whether two motion processes actually exist (Cavanagh \& Mather, 1989), we will refer to the two types of motion displays used in these experiments as short-range and long-range AM. This terminology is mainly based on the attributes of our stimuli-that is, short-range AM to represent moving stimuli undergoing small spatial displacements with no interstimulus intervals (ISIs) and long-range AM to represent moving stimuli undergoing large spatial displacements with ISIs.

2 . This refresh rate was achieved on the IBM PC by using Borland's high-resolution VGA graphics mode rather than the VGA medium/EGA high-resolution mode used by Tipper et al. (1994). All motion displays in the reported experiments were timed and were always within $2 \mathrm{msec}$ of the reported SOA. The 2-msec error in SOAs was due to the video graphics card cycling at slightly faster than $60 \mathrm{~Hz}$.

3. We use SOA to refer to the cue-to-target stimulus onset asynchrony. This is in contrast to ISI, which we used to refer to the interval between two successive frames in an AM display.

4. This change was made for a different experiment and was subsequently adopted for the remaining experiments reported in this paper. On the basis of the consistency of the results, it is unlikely that this change produced any differences in the experimental outcomes and rather represents the flexibility of these orienting effects to different types of displays.

(Manuscript received January 14, 1997; revision accepted for publication May 6, 1998.) 